\title{
Electron-beam lithographic grafting of functional polymer structures from fluoropolymer substrates
}

Katarzyna Gajos ${ }^{1,2}$, Vitaliy A. Guzenko², Matthias Dübner ${ }^{2}$, Jakub Haberko ${ }^{3}$, Andrzej Budkowski ${ }^{1}$, Celestino Padeste ${ }^{2}$

${ }^{1}$ M. Smoluchowski Institute of Physics, Jagiellonian University, Łojasiewicza 11, 30-348 Kraków, Poland

${ }^{2}$ Laboratory of Micro- and Nanotechnology, Paul Scherrer Institute, CH-5232 Villigen, Switzerland

${ }^{3}$ Faculty of Physics and Applied Computer Science, AGH University of Science and Technology, Mickiewicza 30, 30-059 Kraków, Poland 

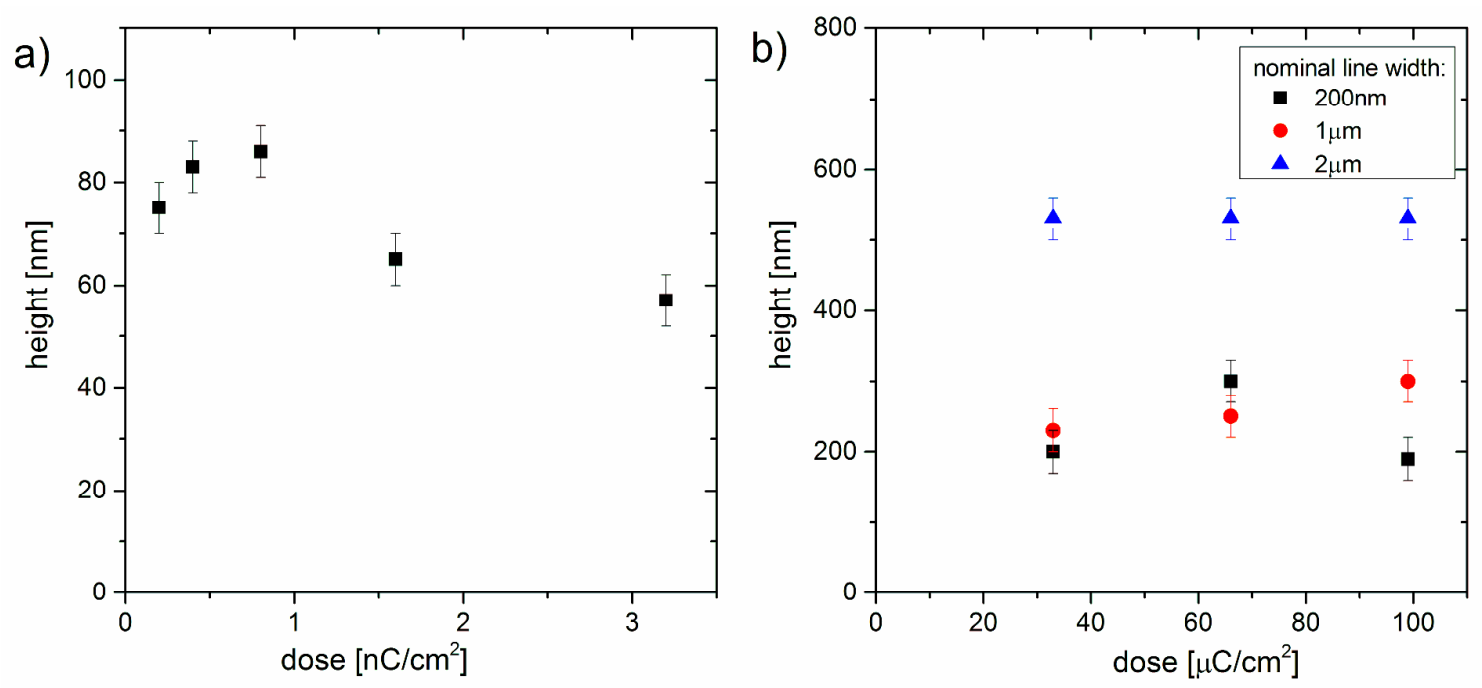

Figure S1. Dose dependence of the height of structures grafted from ETFE after defining radical patterns with EBL at (a) $2.5 \mathrm{keV}$ and (b) $100 \mathrm{keV}$.
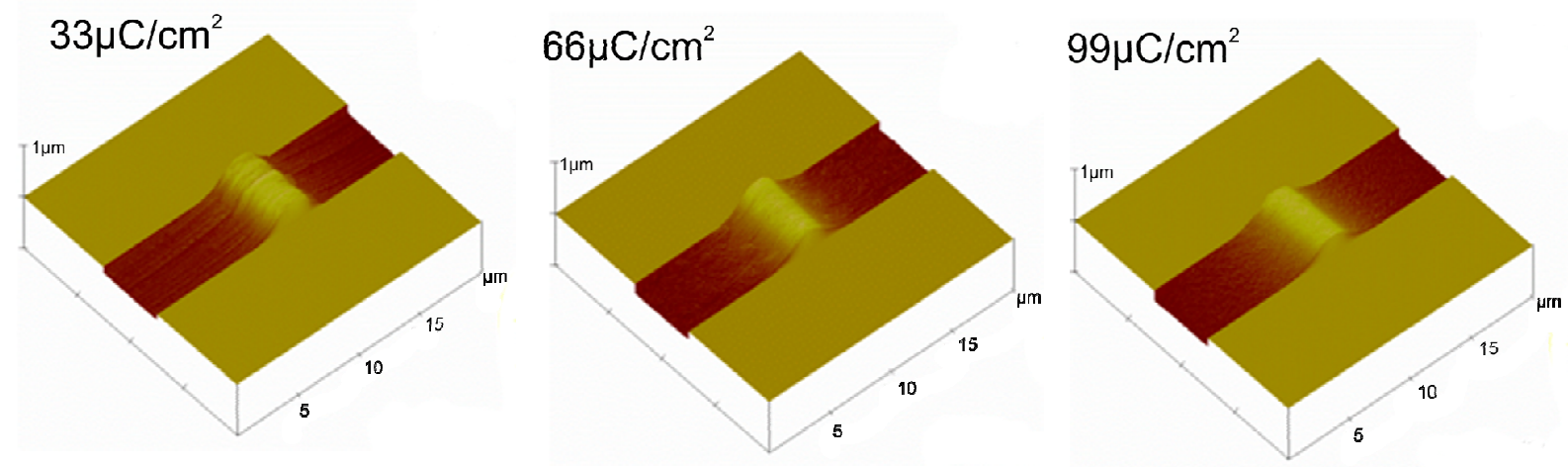

Figure S2. AFM images of PDMAEMA line structures grafted from ETFE after defining radical patterns with $100 \mathrm{keV}$ EBL with $2 \mu \mathrm{m}$ nominal line width and different doses. 


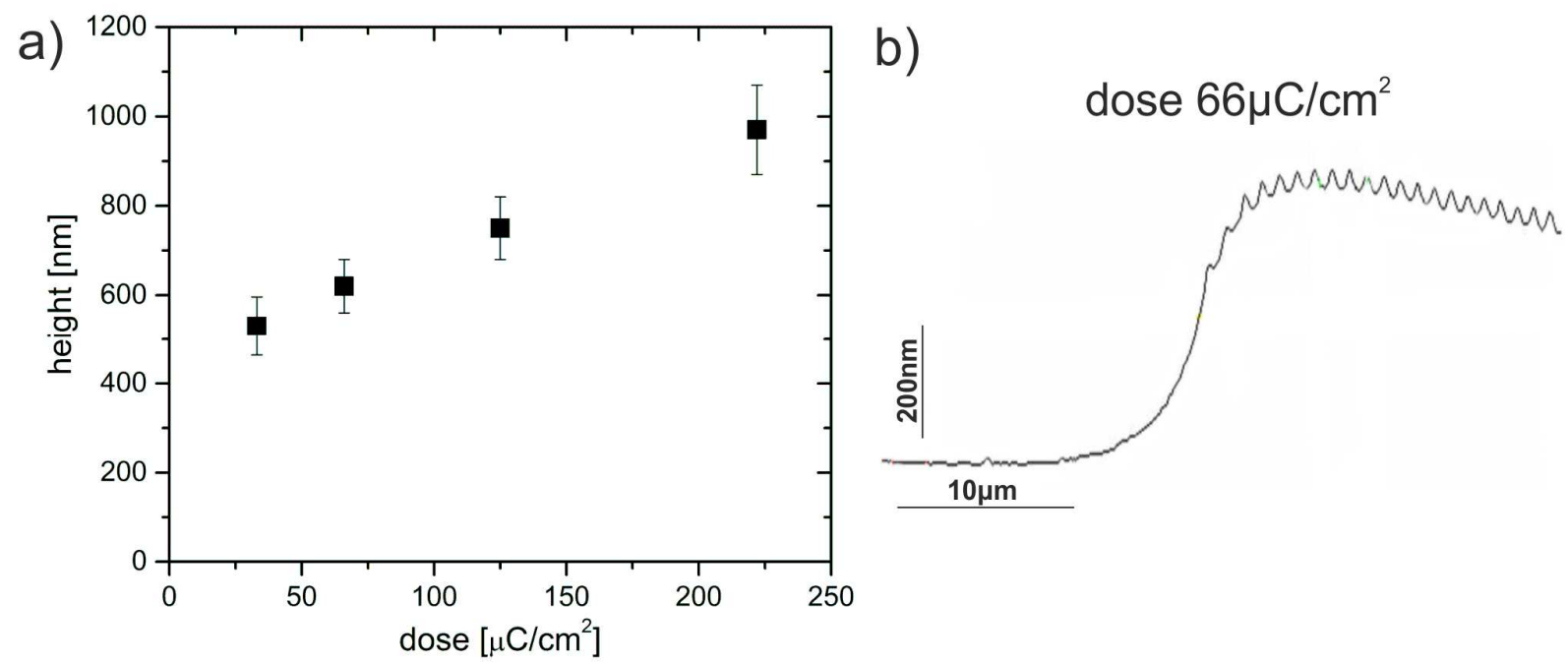

Figure S3. (a) Dose dependence of the AFM-determined height of a cushion formed on ETFE substrate after grafting of PDMAEMA line structures exposed with $1 \mu \mathrm{m}$ distance using $100 \mathrm{keV}$ EBL. (b) cross-section perpendicular to the line structures showing the individual lines on top of the cushion resulting from sub-surface grafting. 
a)

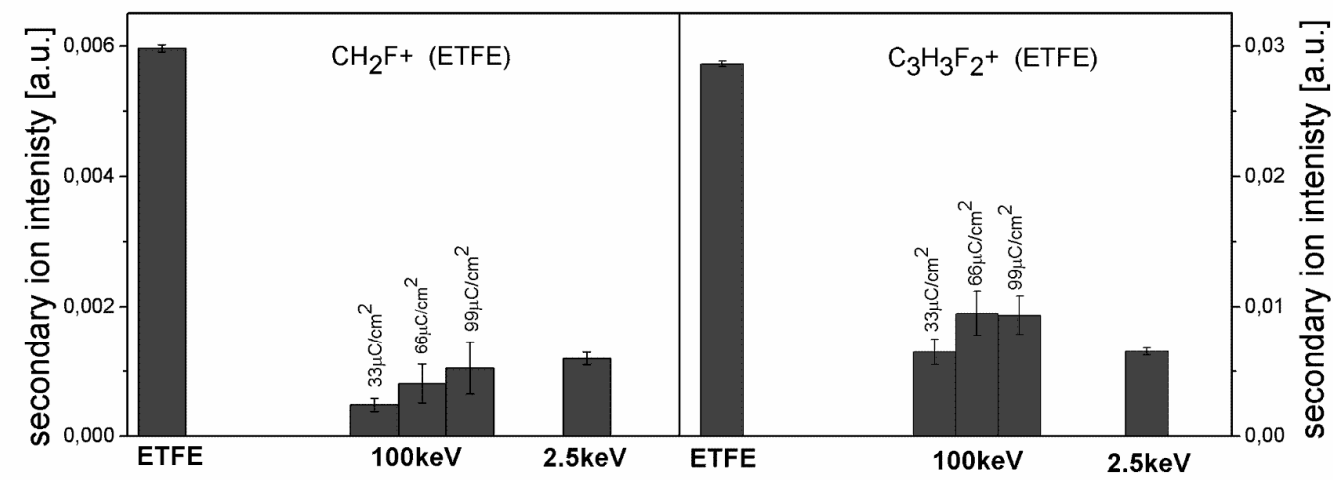

b)

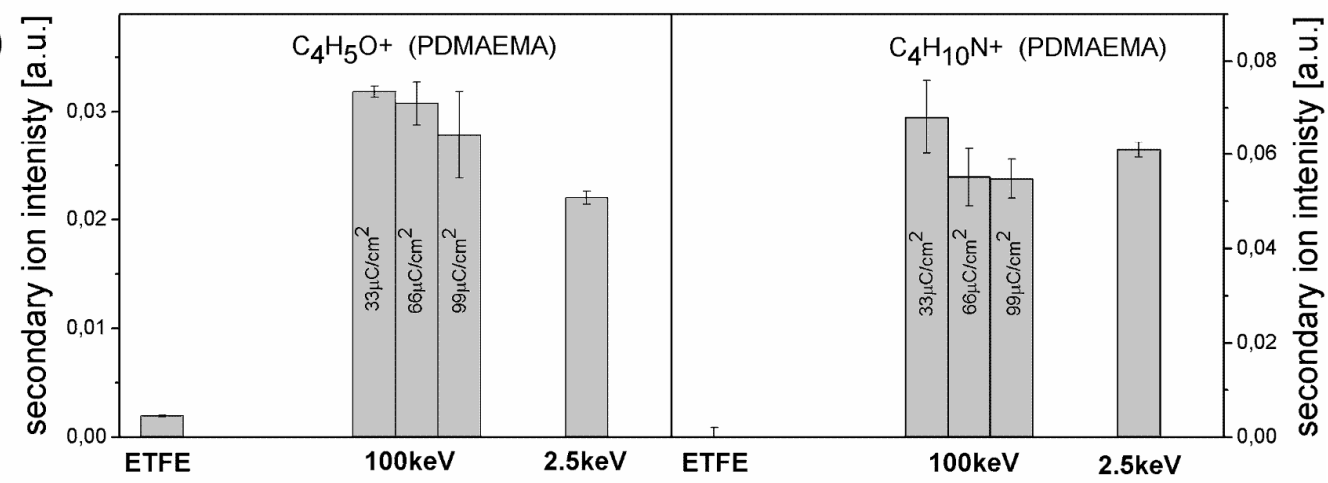

Figure S4. Normalized TOF-SIMS intensities of secondary ions characteristic for (a) ETFE $\left(\mathrm{CH}_{2} \mathrm{~F}^{+}\right.$ and $\left.\mathrm{C}_{3} \mathrm{H}_{3} \mathrm{~F}_{2}{ }^{+}\right)$and (b) PDMAEMA polymer $\left(\mathrm{C}_{4} \mathrm{H}_{5} \mathrm{O}^{+}\right.$and $\left.\mathrm{C}_{4} \mathrm{H}_{10} \mathrm{~N}^{+}\right)$determined for pristine ETFE, and ETFE after PDMAEMA-grafting following activation with $100 \mathrm{keV}$ and $2.5 \mathrm{keV}$ electrons. 


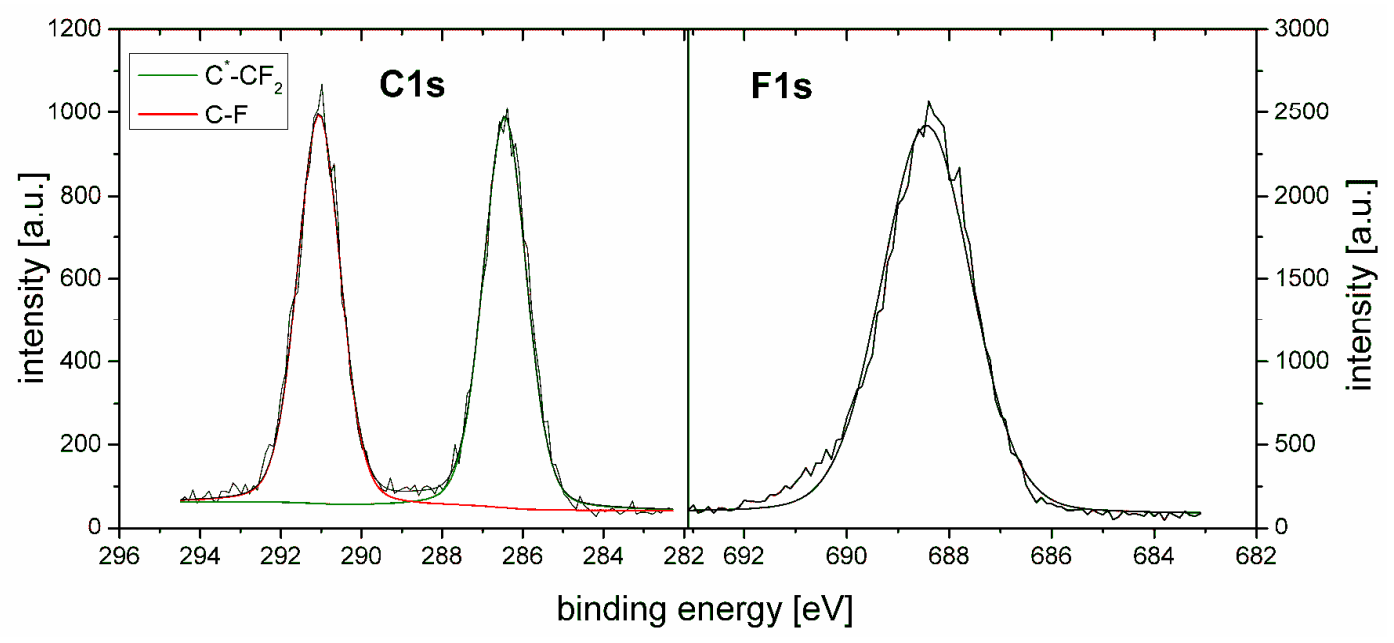

Figure S5. High resolution XPS spectra of $\mathrm{C} 1 \mathrm{~s}$ and $\mathrm{F} 1 \mathrm{~s}$ determined for untreated ETFE film.

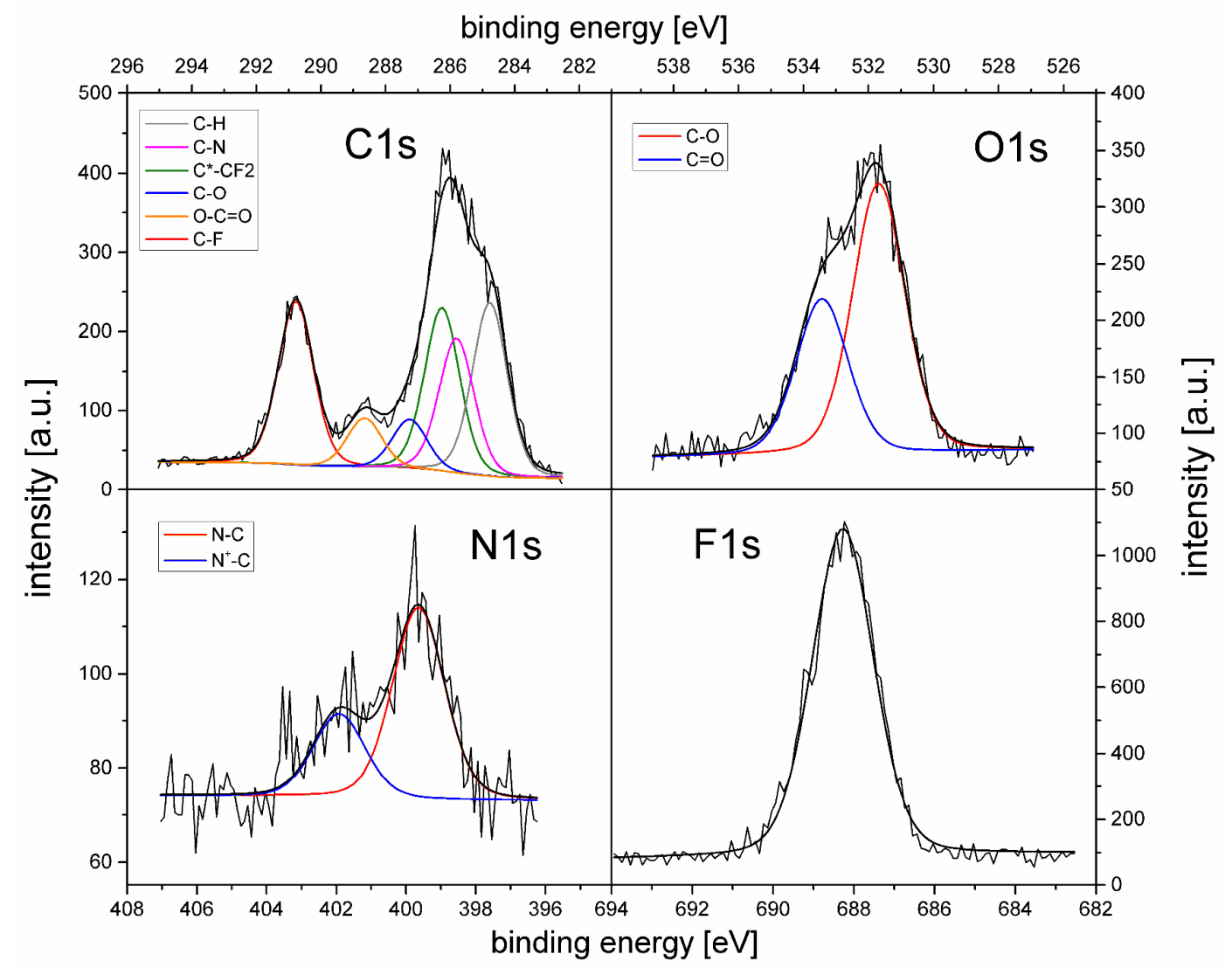

Figure S6. High resolution XPS spectra of C1s, O1s, N1s and F1s core shell determined for ETFE films after PDMAEMA grafting following activation with $100 \mathrm{keV}$ electrons. 


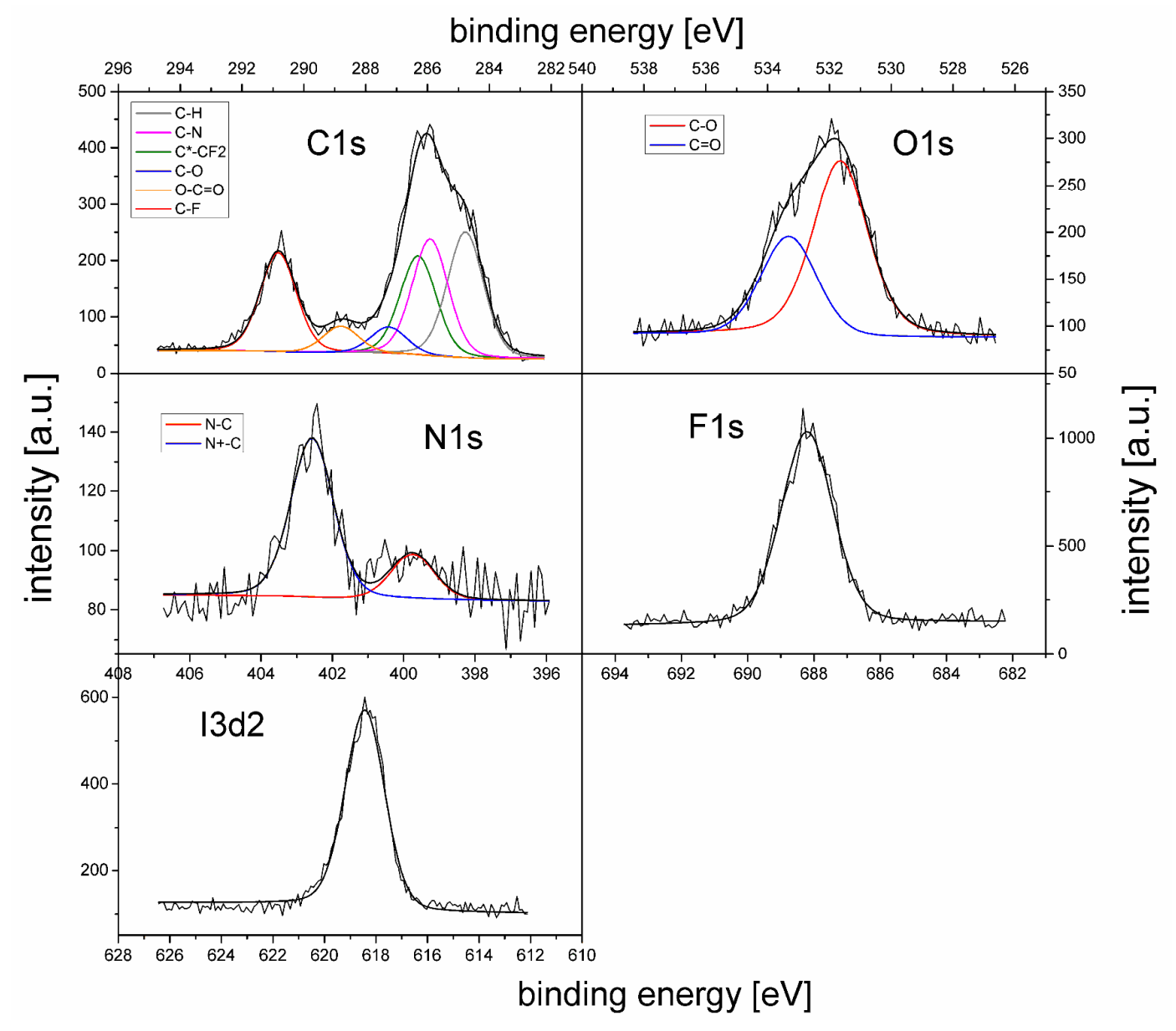

Figure S7. High resolution XPS spectra of C1s, O1s, N1s, F1s and I3d2 core shell determined for ETFE films after PDMAEMA grafting following activation with $100 \mathrm{keV}$ electrons and subsequent quaternization reaction. 